\title{
Endowment Effects in Bundles
}

\author{
Swati Dutta \\ Jyoti Prasad Mukhopadhyay \\ Viswanath Pingali
}

W.P. No.2014-06-01

June 2014

The main objective of the working paper series of the IIMA is to help faculty members, research staff and doctoral students to speedily share their research findings with professional colleagues and test their research findings at the pre-publication stage. IIMA is committed to maintain academic freedom. The opinion(s), view(s) and conclusion(s) expressed in the working paper are those of the authors and not that of IIMA.

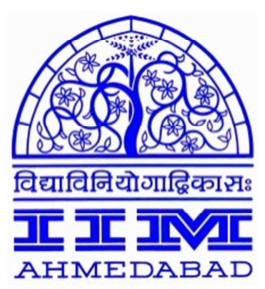

INDIAN INSTITUTE OF MANAGEMENT

AHMEDABAD-380 015

INDIA 


\title{
Endowment Effects in Bundles
}

\author{
Swati Dutta \\ IFMR, Nungambakkam, Chennai, 600030 \\ Email: swati.dutta@ifmr.ac.in \\ Jyoti Prasad Mukhopadhyay \\ IFMR, Numgambakkam, Chennai, 600030 \\ Email: jyoti.mukhopadhyay@ifmr.ac.in \\ Viswanath Pingali \\ Indian Institute of Management Ahmedabad, Vastrapur, Ahmedabad 380015 \\ viswanath@iimahd.ernet.in
}

\begin{abstract}
Behavioral experiments conducted so far to establish existence of endowment effect as propounded by prospect theorists typically endow subjects with a single good. In this paper we depart from this setting by giving subjects initial endowment bundles which consist of two goods: chocolates and pens and directly pit neo-classical theory against prospect theory by comparing divergence between willingness to pay (WTA) and willingness to accept (WTP). Using a novel experimental setting we examine the difference in such divergence for a group that is given physical bundles as endowment vis-à-vis a group which is asked to imagine the same initial endowment bundle in their possession. We find weak evidence of endowment effect. Moreover, we examine how endowment effect of a good changes when units of the other good in initial endowment bundle change. We find no statistically significant evidence of endowment effect of a good being sensitive to the number of units of the other good in initial endowment bundle.
\end{abstract}

Keywords: endowment effect; prospect theory; willingness to pay and willingness to accept

\author{
JEL Classification: C91; D0
}




\section{Endowment Effects in Bundles}

\section{Introduction}

'Endowment effects' refers to the phenomenon where people value a good or a service more when their ownership of the good is unambiguously established. This behavioral trait essentially leads to a divergence between willingness to accept (WTA) and willingness to pay (WTP) for the good once the property rights are well established. While the standard neoclassical literature presumes that preferences are not contingent upon initial endowment, experimental evidence proves otherwise. Proponents of endowment effects theory (Thaler ,1980; Knetsch, 1989) argue that this divergence is due to loss aversion where losses seem to loom larger than gain. Knetsch's (1989) seminal study shows that people who have been endowed with a chocolate bar are less reluctant to trade it for a coffee mug than individuals who were not (and vice-versa), thereby demonstrating the existence of endowment effects. Subsequently, several studies have characterized endowment effects under several alternative settings. For example, Carmon and Ariely (2000) shows how valuations differ for DukeUniversity's basketball tickets between the ones who have tickets and the ones who could not purchase the ticket. Endowment effects also exist for high value markets investments (Odean,1998).

There have also been studies that talk about how endowment effects change as market setup or initial endowments change. Studies also show these endowment effects taper off among the individuals with 'intense market experience' (List, 2004). Presumably, repeated interaction or increasing market experience makes the subjects more 'rational.' In a more recent study, Burson et al. (2013) add to the existing literature on endowment effects by showing that endowment effects are attenuated as the initial endowment of the good 
increases. Interestingly, they also show that, even if the units of measurement are changed, there is no perceivable change in how endowment effects manifest. ${ }^{1}$

In this paper, we answer a more general question: What happens to endowment effects of a good when the endowment of other goods increases? To elaborate further, the primary contribution of this study is to investigate how endowment effect of a good (measured along the horizontal axis) change if we vertically move to a higher or a lower indifference curve in a two-good framework. To this effect, we measure the changes in endowment effects for good $\mathrm{X}$ as the initial endowment of good $\mathrm{Y}$ changes (while keeping endowment of good $\mathrm{X}$ constant). As in the literature, we measure endowment effects as the change in the difference WTA and WTP with and without property rights of initial endowment being established. Therefore, this further allows us to establish the presence of endowment effects in more generalized settings than in the previous literature. Our study is relevant in the context of literature on tying and bundling as marketing tools. As to what happens to the endowment effects when the composition of the bundle changes, can be answered using the results of the study.

To characterize endowment effects in a multi-good framework, we develop a novel experimental design that deviates from the existing designs. First, we maintain an initial endowment consisting of both goods (pens and chocolates) in positive quantities. This allows us to capture endowment effects at an interior point of an indifference curve. Literature so far has only looked at a resultant equilibrium, which is akin to corner solution in the indifference curve literature. The subject is either left with, for example, a coffee mug or a chocolate, but not both. In our study, we do not preclude that the subject has a positive quantity of both goods even after the trade. Second, we ask some respondents to bid for the number of pens

\footnotetext{
${ }^{1}$ In fact, several studies argue that these endowment effects arise in experimental settings due to design issues and subject misconception (Plot and Zeiler (2005, 2007 and 2011), and Isoni et al. (2011)).
} 
they would require to forego a chocolate (WTA), and some other respondents number of pens are willing to forego for one additional chocolate (WTP). In order to elicit true preferences, we use Becker-DeGroot-Marschak (BDM henceforth) mechanism. BDM mechanism, in theory, ensures that the subjects reveal their true preferences (Becker, et al.,1964). Further, this mechanism is widely used in the experimental literature for eliciting true preferences (Knetsch ,1989; List,2004, Isoni et al.,2011). This mechanism enables us to compute WTA and WTP for good X (chocolates) in terms of good Y (pens) for various endowment levels of pens (while keeping endowment for chocolates fixed). Further, this allows us to measure WTA and WTP without any reference to money. It may be argued that with money being more fungible, it can distort subjects' 'mental accounting' and hence, estimation of potential gains and losses (Thaler (1985)).

Our results show that median WTP of subjects with imaginary endowments exceeded that of subjects with same initial endowment but in physical units. However, in case of WTA experiments we did not find any statistically significant difference in median WTA between subjects with physical units of pens and chocolates as initial endowments and imaginary units of pens and chocolates as initial endowments. Therefore, we found weak evidence of endowment effect in the two-good setting (chocolates and pens). We found no statistically significant impact of change in number of units of pens in initial endowment on the endowment effect of chocolates.

The rest of the paper is organized as follows: Section 2 describes theoretical framework and the main hypotheses. In Section 3, we describe the design of the experiments. Section 4 describes the empirical model. Section 5 reports the results of the experiments, and Section 6 concludes. 


\section{Theoretical Framework and Hypotheses}

In order to answer our main research question, we first define what we mean by endowment effect. Endowment effects are defined as the difference between willingness to accept (WTA) and willingness to pay (WTP) when a person is endowed with a bundle of goods when compared to not being endowed with the goods. To elaborate further, we choose two goods: pens and chocolates. The goods have been chosen after a pilot experiment which showed that these two are equally preferable; these results are available with the authors. Figure 1 explains the idea of endowment effects, where Good X is the chocolate and Good Y, pens. The indifference curve of the consumer under neo-classical setting is the thick line given by IC. Standard neo-classical theory predicts that the shape of indifference curve does not depend on the endowment of the consumer. On the contrary, presence of endowment effects would mean that the consumers' preferences would be contingent on the endowments of the consumer. The initial endowment bundle is given by bundle $\left(\mathrm{x}_{0}, \mathrm{y}_{0}\right)$ which represents $\mathrm{x}_{0}$ and $y_{0}$ units of chocolates and pens respectively. Endowment effect causes a kink in the solid IC at the initial endowment bundle $\left(\mathrm{x}_{0}, \mathrm{y}_{0}\right)$. The new indifference curve under prospect theory is the dotted line, IC'. We represent WTP for $\mathrm{x}_{1}$ under prospect theory and under neoclassical by WTP $\left(\mathrm{x}_{1} \mid \mathrm{P}\right)$ and WTP $\left(\mathrm{x}_{1} \mid \mathrm{NC}\right)$ respectively. Similarly, we represent WTA for $\mathrm{x}_{1}$ under prospect theory and under neoclassical by WTA $\left(\mathrm{x}_{-1} \mid \mathrm{P}\right)$ and WTA $\left(\mathrm{x}_{-1} \mid \mathrm{NC}\right)$ respectively.

From Figure 1 the following magnitudes are evident:

$$
\begin{aligned}
& \operatorname{WTP}\left(\mathrm{x}_{1} \mid \mathrm{P}\right)=\mathrm{AB} ; \operatorname{WTP}\left(\mathrm{x}_{1} \mid \mathrm{NC}\right)=\mathrm{AC} \\
& \operatorname{WTA}\left(\mathrm{x}_{-1} \mid \mathrm{P}\right)=\mathrm{DF} ; \mathrm{WTA}\left(\mathrm{x}_{-1} \mid \mathrm{NC}\right)=\mathrm{DE}
\end{aligned}
$$

Clearly, WTP $\left(\mathrm{x}_{1} \mid \mathrm{NC}\right)=\mathrm{AC}>\mathrm{WTP}\left(\mathrm{x}_{1} \mid \mathrm{P}\right)=\mathrm{AB}$ and 
WTA $\left(\mathrm{x}_{-1} \mid \mathrm{P}\right)=\mathrm{DF}>\mathrm{WTA}\left(\mathrm{x}_{-1} \mid \mathrm{NC}\right)=\mathrm{DE}$

Hence,

WTA $\left(\mathrm{x}_{-1} \mid \mathrm{P}\right)-\mathrm{WTP}\left(\mathrm{x}_{1} \mid \mathrm{P}\right)=\mathrm{DF}-\mathrm{AB}>\mathrm{WTA}\left(\mathrm{x}_{-1} \mid \mathrm{NC}\right)-\mathrm{WTP}\left(\mathrm{x}_{1} \mid \mathrm{NC}\right)=\mathrm{DE}-\mathrm{AC}$

We measure the endowment effect as the difference in difference between WTA and WTP between IC' and IC due to this endowment effect induced kink at the initial endowment bundle.

Figure -1

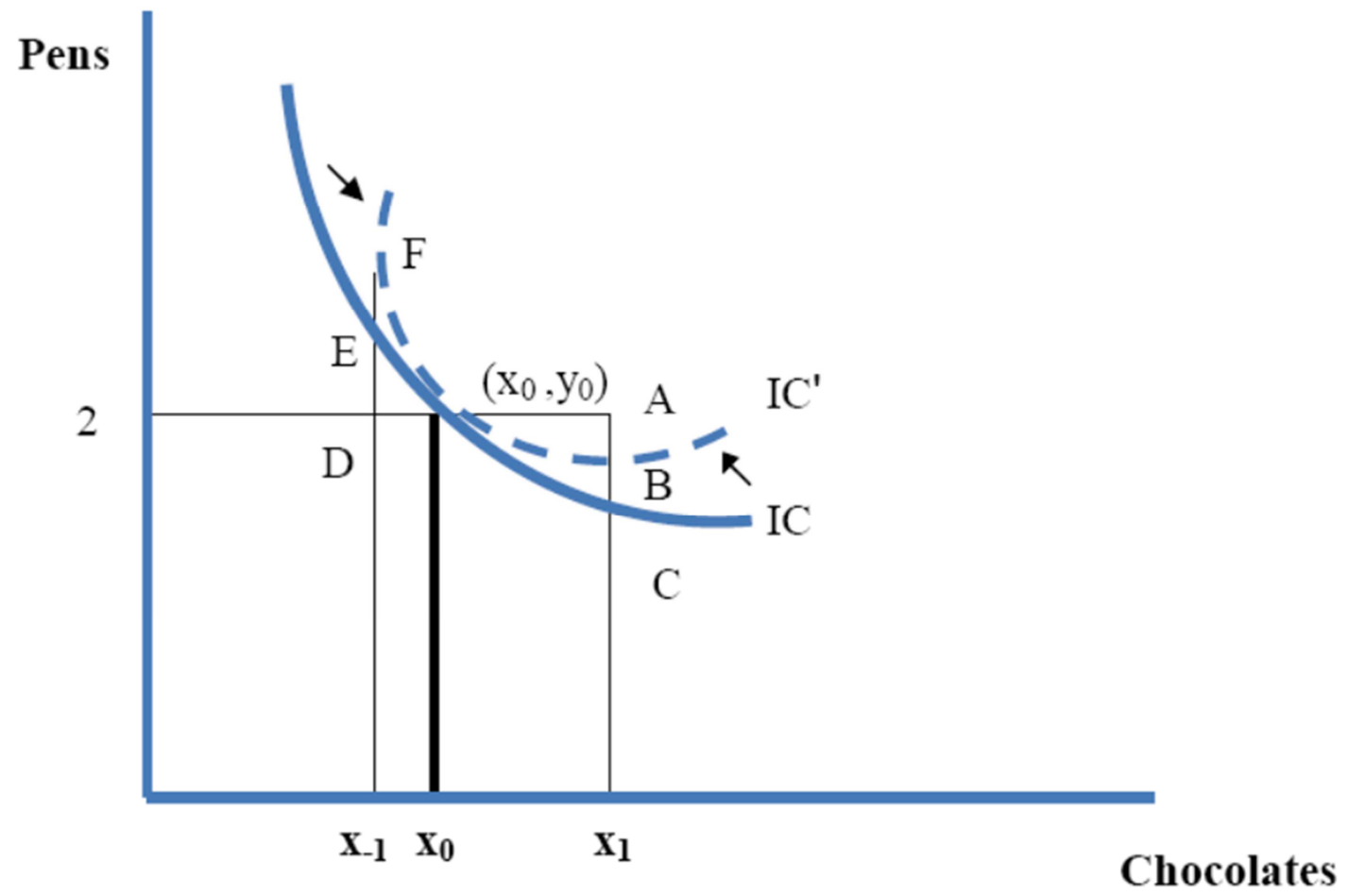

We explain the second main hypothesis of this paper in Figure 2. Suppose there are two bundles where, $\mathrm{W}_{1}$ represents two pens and two chocolates, and $\mathrm{W}_{2}$ represents three pens and two chocolates. Since both goods are positively preferred, it is obvious that $\mathrm{W}_{2}$ lies on a higher indifference curve $\left(\mathrm{IC}_{2}\right)$ than $\mathrm{W} 1\left(\mathrm{IC}_{1}\right)$. Here we ask how the endowment effect would change as the initial endowment moves from $\mathrm{W}_{1}$ to $\mathrm{W}_{2}$. 
Figure -2

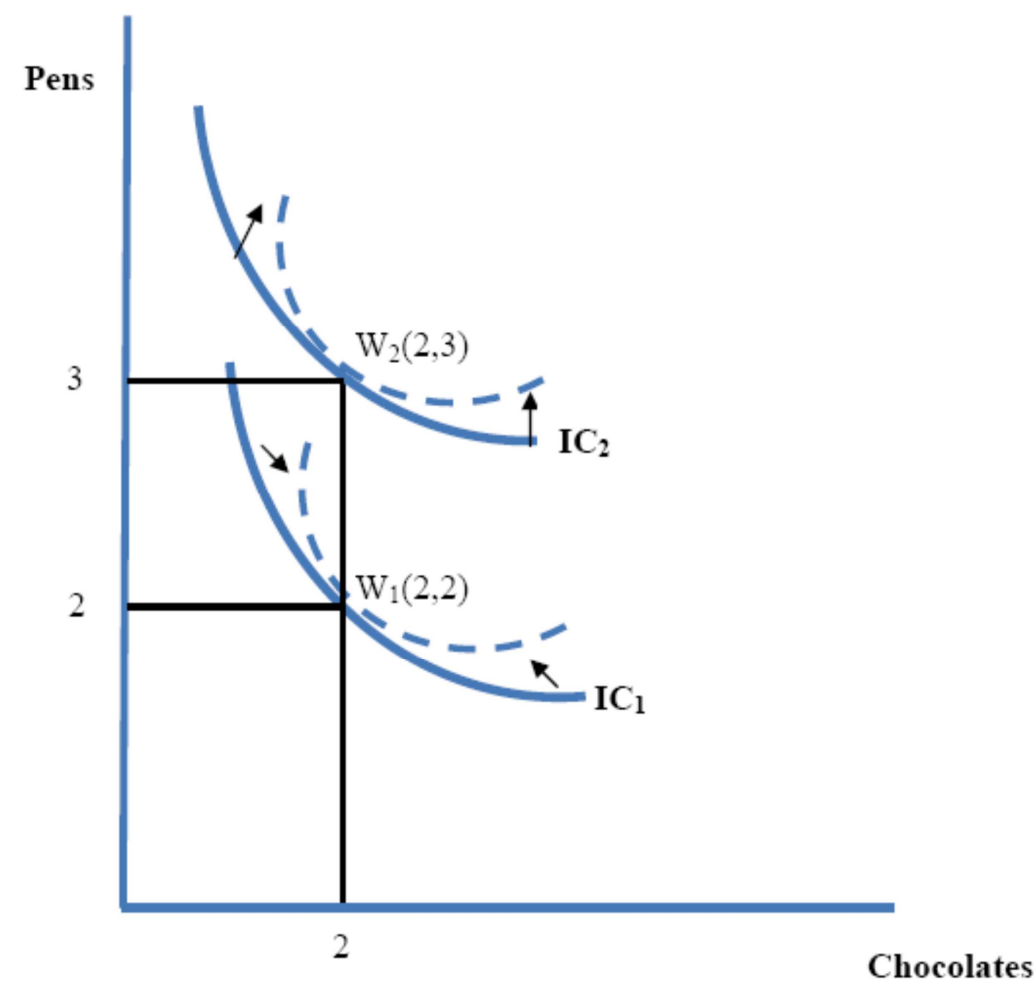

\section{Experimental Design}

Our experimental design, described below, accounts for some of the important features highlighted in the literature. For example, like in the literature we do not elicit preferences in the form of cash, but in terms of other goods. In order to elicit subjects' preferences we use BDM mechanism. Under the BDM, a subject bids for an item and subsequently the item's price is decided on the basis of a random lottery. In the purchase situation (WTP), if the bid is above (below) the random price, then the subjects receive (do not get) the item in question and pay the random price (pay nothing); and in the sale situation (WTA), if the bid is below (above) the random price, then subjects will (not) sell the item at the random price. It can be shown that BDM is incentive compatible and can elicit true preferences. The behavioral literature is also full of examples that use BDM for preference elicitation (Knetsch, 1989; List 2004; Isoni et al., 2011). According to Ariely et al. (2005) the 
"BDM procedure ensures that all participants have a (weakly) dominant strategy to reveal their maximum willingness to pay (WTP) [or minimum willingness to accept (WTA)] truthfully."2 We also control for procedural bias highlighted, for example, in Plott and Zeiler (2011). To be more specific, Plott and Zeiler (2011) say that the 'subject misconception' arising out of not having a good understanding of the rules of the game is often mistaken as endowment effect. We address this issue by walking the subjects through examples on how the bidding mechanism works.

The question we pose in this paper is answered through the following four experiments. All subjects are randomly assigned to the experiments. We conducted these experiments in two business schools in Chennai, India: IFMRBusinessSchool, and Loyola Institute of Business Administration (LIBA). Both schools are geographically close to each other, and are similarly ranked (among the top 30 programs in business management education in India. ${ }^{3}$ The students are first year, and second year students pursuing their post graduate diploma in business management (equivalent to MBA). These experiments have been conducted over two year window (2011 to 2013) to avoid any contamination arising between students who participated in the experiments and those who did not.

\section{Experiment A 1:}

In this experiment the subjects were divided into two groups: Group 1 and Group 2. Participants of both the groups were given 2 chocolates and 2 pens as initial endowments. The subjects were given a brief explanation of how the BDM bidding mechanism works using appropriate illustrations. In order to avoid any biases, BDM bidding mechanism was illustrated using a power point presentation by an independent experimenter (with a script).

\footnotetext{
${ }^{2}$ There have also been some studies that show that BDM is not the right mechanism for eliciting preferences (Horowitz, 2006). However, as there is no reason to believe a priori that this bias is non-random, this is still appropriate for answering our research question.

${ }^{3}$ http://www.outlookindia.com/articlefullwidth.aspx?238497
} 
The experimenter has no knowledge of the main objective of this study. Then, participants in one of the groups (Group-1) were given an option of receiving an additional chocolate, for which they have to forego pens (WTP). ${ }^{4}$ They were told that the end outcome - on whether they receive a chocolate or not - is determined using a BDM mechanism, and therefore, it is in their best interest to bid the actual value. The students were asked to write their bids secretly on a piece of paper and return it to the examiner. Then, the random draw was conducted using two cards with 0 pens, 1 pen and 2 pens written on them. The exchange rule was as follows:

- If the number of pens written on the card drawn at random is higher than the maximum number of pens that a particular participant has quoted then there were no exchanges.

- If the number of pens written on the card drawn at random is smaller than or equal to the maximum number of pens that a particular participant has quoted then that participant has to accept the chocolate by foregoing the number of pens written on the drawn card.

Participants in the other group (Group 2) were given an option to forego an additional chocolate in exchange of pens. They were asked to submit a bid where they specify the minimum number of pens they require to forego that chocolate (WTA). Everything is similar to Group 1, except the exchange rule, which is determined as follows:

- If the number of pens written on the card drawn at random is less than the minimum number of pens that a particular participant has quoted then there will be no exchange.

\footnotetext{
${ }^{4}$ Intuitively speaking a rational individual will quote the maximum number of pens in such a way that after trade the individual either will remain on the same indifference curve or will attain an indifference curve representing a higher utility level.
} 
- If the number of pens written on the card drawn at random is greater than or equal to the minimum number of pens that a particular participant has quoted then that participant will have to forego the chocolate in exchange of number of pens written on the drawn card.

\section{Experiment B1:}

In this experiment, like in A1, the subjects were divided into two groups: Group1 and Group 2. All these participants were asked to imagine that they possess 2 chocolates and 2 pens. In order to rule out any ambiguity, the experimenter showed these two goods to the participants for them to inspect. Upon inspection, the subjects returned the goods to the experimenter. The rest of the experiment is similar to the one described in A1.

\section{Experiment A2:}

This experiment is similar to A1, except that the initial endowment is 2 chocolates and 3 pens.

\section{Experiment B2:}

The experiment is similar to B1, except that the initial endowment is 2 chocolates and 3 pens.

Table 1 presents the details on the sample composition, and spread across the four experiments.

Table 1: Sample Composition

\begin{tabular}{|cc|}
\hline $\begin{array}{c}\text { Experiment group } \\
\text { With Endowment Groups }\end{array}$ & No of subjects \\
& \\
A1-WTA & 34 \\
A1-WTP & 36 \\
A2-WTA & 41 \\
A2-WTP & 35 \\
Without Endowment Groups & \\
& \\
B1-WTA & 44 \\
B1-WTP & 42 \\
B2-WTA & 35 \\
B2-WTP & 46 \\
Total & $\mathbf{3 1 3}$ \\
\hline
\end{tabular}


Notes: A1/B1: 2 Reynolds Pens and 2 Dairy Milk chocolates group; A2/B2: 3 Reynolds Pens and 2 Dairy Milk chocolates group

\section{Empirical model}

Based on above experiment design we formulate the following hypotheses:

\section{Hypothesis 1:}

The difference between WTA and WTP is significantly greater for the groups that are endowed with the initial bundle when compared to the group that was not endowed with the initial bundle.

$\mathrm{H}_{0}:\{\mathrm{WTA}(\mathrm{A} 1)-\mathrm{WTP}(\mathrm{A} 1)\}-\{\mathrm{WTA}(\mathrm{B} 1)-\mathrm{WTP}(\mathrm{B} 1)\}=0$

$\mathrm{H}_{\mathrm{A}}:\{\mathrm{WTA}(\mathrm{A} 1)-\mathrm{WTP}(\mathrm{A} 1)\}-\{\mathrm{WTA}(\mathrm{B} 1)-\mathrm{WTP}(\mathrm{B} 1)\}>0$

Similarly for A2 and B2

\section{Hypothesis 2:}

The WTA and WTP difference for Good X between the subjects endowed with the initial bundle and the ones not endowed with the initial bundle changes for good $\mathrm{X}$ as the endowment for Good Y changes. Formally,

$\mathrm{H}_{0}:[\{$ WTA $(\mathrm{A} 1)-\mathrm{WTP}(\mathrm{A} 1)\}-\{$ WTA $(\mathrm{B} 1)-\mathrm{WTP}(\mathrm{B} 1)\}]-[\{$ WTA $(\mathrm{A} 2)-\mathrm{WTP}$

$$
(\mathrm{A} 2)\}-\{\mathrm{WTA}(\mathrm{B} 2)-\mathrm{WTP}(\mathrm{B} 2)\}]=0
$$

$\mathrm{H}_{\mathrm{A}}:[\{\mathrm{WTA}(\mathrm{A} 1)-\mathrm{WTP}(\mathrm{A} 1)\}-\{$ WTA $(\mathrm{B} 1)-\mathrm{WTP}(\mathrm{B} 1)\}]-[\{$ WTA $(\mathrm{A} 2)-\mathrm{WTP}$

$$
(\mathrm{A} 2)\}-\{\text { WTA }(\mathrm{B} 2)-\mathrm{WTP}(\mathrm{B} 2)\}] \neq 0
$$

In order to prove the above hypotheses, we use the following empirical specification:

$Y_{i}=\alpha+\beta_{1} D_{1 i}+\beta_{2} D_{2 i}+\beta_{3} D_{3 i}+\delta_{1} D_{1 i} D_{2 i}+\delta_{2} D_{1 i} D_{3 i}+\delta_{3} D_{2 i} D_{3 i}+\gamma_{1} D_{i 1} D_{2 i} D_{3 i}+\epsilon_{i}$ 
The explanation for various terms is given below:

\begin{tabular}{|l|l|}
\hline Variable & \multicolumn{1}{|c|}{ Explanation } \\
\hline$Y_{i}$ & Bid of Subject $i$ \\
\hline$D_{\mathbf{1}}$ & Takes value 1 if the bid pertains to WTA, 0 if the bid pertains to WTP \\
\hline$D_{\mathbf{2}}$ & Takes value 1 if the subject is endowed with the initial bundle, 0 otherwise \\
\hline$D_{\mathbf{3}}$ & $\begin{array}{l}\text { Takes value 1 if the subject belongs to } \mathrm{W}_{2} \text { group (3 pens and 2 chocolates) } \\
\text { and zero if the subject belongs to } \mathrm{W}_{1} \text { group (2 chocolates and 2 pens) }\end{array}$ \\
\hline
\end{tabular}

Based on the empirical specification, consider the following cases:

\begin{tabular}{|c|c|c|c|c|c|}
\hline Case & $D_{1}$ & $D_{2}$ & $D_{3}$ & Outcome & Significance \\
\hline Base & 0 & 0 & 0 & $\alpha$ & WTP (B1) \\
\hline 1 & 1 & 0 & 0 & $\alpha+\beta_{1}$ & WTA (B1) \\
\hline 2 & 0 & 1 & 0 & $\alpha+\beta_{2}$ & WTP (A1) \\
\hline 3 & 0 & 0 & 1 & $\alpha+\beta_{3}$ & WTP (B2) \\
\hline 4 & 1 & 1 & 0 & $\alpha+\beta_{1}+\beta_{2}+\delta_{1}$ & WTA (A1) \\
\hline 5 & 1 & 0 & 1 & $\alpha+\beta_{1}+\beta_{3}+\delta_{2}$ & WTA (B2) \\
\hline 6 & 0 & 1 & 1 & $\alpha+\beta_{2}+\beta_{3}+\delta_{3}$ & WTP (A2) \\
\hline 7 & 1 & 1 & 1 & $\alpha+\beta_{1}+\beta_{2}+\beta_{3}+\delta_{1}+\delta_{2}+\delta_{3}+\gamma$ & WTA (A2) \\
\hline
\end{tabular}

Based on this, we can calculate the following:

$$
\begin{aligned}
& \operatorname{WTA}\left(\mathrm{A}_{1}\right)-\operatorname{WTP}\left(\mathrm{A}_{1}\right)=\beta_{1}+\delta_{1} \\
& \operatorname{WTA}\left(\mathrm{B}_{1}\right)-\operatorname{WTP}\left(\mathrm{B}_{1}\right)=\beta_{1}
\end{aligned}
$$

Therefore, the first hypothesis can be stated as follows: 
$H_{0}: \delta_{1}=0$

$H_{A}: \delta_{1}>0$

Similarly, the second hypothesis can be restated as follows:

$H_{0}: \gamma=0$

$H_{A}: \gamma \neq 0$

\section{Results}

We present summary statistics of all the different treatment groups in Table 2. We first discuss experiment results for the groups with $\mathrm{W}_{1}$ (2 chocolates and 2 pens) as initial endowments. Table 2 shows that median WTA ( 2 pens) of the subjects who were given physical endowments in experiment A1 equaled that of ( 2 pens) of subjects who were asked to imagine so in experiment B1. This runs counter to the pivot around the endowment bundle we conjectured in Section 2. We test this formally using Mann-Whitney-Wilcoxon U test, and the results are presented in Table 3 . We fail to reject the null of equal medians (z-statistic $=1.052 ; \mathrm{p}$-value is high) at any conventional levels of significance. Interestingly, we find that median WTP (0 pens) of subjects with initial endowments in experiment A1 is less than that (1 pen) of subjects with imaginary endowments in experiment B1. From Table 3, it is evident that this difference is statistically significant at $1 \%$ level of significance (z-statistic $=-2.87$ ). This is in line with what we theoretically conjectured in Section 2.

We now turn to the experiment groups with $\mathrm{W}_{2}(2$ chocolates and 3 pens $)$ as initial endowments. For experiment groups under $\mathrm{W}_{2}$ (2 chocolates and 3 pens) we find qualitatively similar results. Table 2 shows that median WTA ( 2 pens) of the subjects who were given physical endowments in experiment A2 equaled that of ( 2 pens) of subjects who were asked to imagine so in experiment B2. Mann-Whitney-Wilcoxon test results shows that 
we fail to reject the null of equal medians (z-statistic $=-0.405$; p-value is high) at any conventional levels of significance. Interestingly, we find that median WTP ( 0 pens) of subjects with initial endowments in experiment A1 is less than that (1 pen) of subjects with imaginary endowments in experiment B1. From Table 3, it is evident that this difference is statistically significant at $5 \%$ level of significance $(\mathrm{z}$-statistic $=-1.84)$. Combining the WTA and WTP results for experiment groups with $\mathrm{W}_{1}\left(2\right.$ chocolates and 2 pens) and $\mathrm{W}_{2}(2$ chocolates and 3 pens) as initial endowments, we find that $\{$ WTA (A1) - WTP (A1) $\}-$ $\{$ WTA $(\mathrm{B} 1)-\mathrm{WTP}(\mathrm{B} 1)\}>0$. The same is true in case of A2 and B2 as well. In other words, we find some weak ${ }^{5}$ evidence in favour of existence of endowment effect.

Table 2: Summary Statistics of Bids of Different Experiment Groups Summary Statistics of Bids of Different Experiment Groups

\begin{tabular}{|c|c|c|c|c|c|c|}
\hline $\begin{array}{l}\text { Experiment } \\
\text { Group }\end{array}$ & Mean & Median & Std & Maximum & Minimum & Count \\
\hline \multicolumn{7}{|c|}{ With Endowment Groups } \\
\hline A1-WTA & 1.76 & 2 & 1.15 & 5 & 0 & 34 \\
\hline A1-WTP & 0.5 & 0 & 0.654 & 2 & 0 & 36 \\
\hline A2-WTA & 2.21 & 2 & 1.50 & 8 & 0 & 41 \\
\hline A2-WTP & 0.88 & 1 & 0.93 & 3 & 0 & 35 \\
\hline \multicolumn{7}{|c|}{ Without Endowment Groups } \\
\hline B1-WTA & 1.93 & 2 & 2.94 & 20 & 0 & 44 \\
\hline B1-WTP & 0.95 & 1 & 0.70 & 2 & 0 & 42 \\
\hline B2-WTA & 2.5 & 2 & 1.8 & 10 & 0 & 35 \\
\hline B2-WTP & 1.19 & 1 & 0.83 & 3 & 0 & 46 \\
\hline
\end{tabular}

Notes: A1/B1: 2 Reynolds Pens and 2 Dairy Milk chocolates group; A2/B2: 3 Reynolds Pens and 2 Dairy Milk chocolates group

Table 3: Mann-Whitney-Wilcoxon U Test Results

\begin{tabular}{|c|c|}
\hline Hypothesis & Mann-Whitney Wilcoxon U Test statistic \\
\hline Endowment bundle : $\mathbf{W}_{\mathbf{1}}$ (2 Chocolates and 2 Pens) \\
\hline Ho: median WTA(B1) = median WTP(B1) & $\mathrm{z}=2.981^{* * *}$ \\
$\mathrm{H}_{\mathrm{A}}:$ median WTA(B1) > median WTP(B1) & $(0.000)$ \\
\hline Ho: median WTP(A1) = median WTP(B1) & $\mathrm{z}=-2.879^{* *}$ \\
$\mathrm{H}_{\mathrm{A}}:$ median WTP(A1) < median WTP(B1) & $(0.000)$ \\
\hline Ho: median WTA(A1) = median WTP(A1) & $\mathrm{z}=4.993^{* * *}$ \\
\hline
\end{tabular}

\footnotetext{
${ }^{5}$ We call it weak because we do not find evidence in favour of pivot of IC around the initial endowment bundle for WTA experiment groups.
} 


\begin{tabular}{|c|c|}
\hline $\mathrm{H}_{\mathrm{A}}:$ median WTA(A1) $>$ median WTP(A1) & $(0.000)$ \\
\hline Ho: median WTA $(\mathrm{A} 1)=$ median WTA(B1) & $\mathrm{z}=1.052$ \\
\hline $\mathrm{H}_{\mathrm{A}}:$ median $\mathrm{WTA}(\mathrm{A} 1)>$ median $\mathrm{WTA}(\mathrm{B} 1)$ & $(0.290)$ \\
\hline \multicolumn{2}{|c|}{ Endowment bundle : $W_{2}(2$ Chocolates and 3 Pens $)$} \\
\hline Ho: median WTA(B2) = median WTP(B2) & $\mathrm{z}=4.605 * * *$ \\
\hline $\mathrm{H}_{\mathrm{A}}$ : median $\mathrm{WTA}(\mathrm{B} 2)>$ median $\mathrm{WTP}(\mathrm{B} 2)$ & $(0.000)$ \\
\hline Ho: median WTP(A2) = median WTP $(\mathrm{B} 2)$ & $\mathrm{z}=-1.847 * *$ \\
\hline $\mathrm{H}_{\mathrm{A}}$ : median WTP $(\mathrm{A} 2)<$ median WTP $(\mathrm{B} 2)$ & $(0.05)$ \\
\hline Ho: median WTA(A2) = median WTP(A2) & $\mathrm{z}=4.481 * * *$ \\
\hline $\mathrm{H}_{\mathrm{A}}$ : median WTA(A2) $>$ median $\mathrm{WTP}(\mathrm{A} 2)$ & $(0.000)$ \\
\hline Ho: median $\mathrm{WTA}(\mathrm{A} 2)=$ median $\mathrm{WTA}(\mathrm{B} 2)$ & $\mathrm{z}=-0.405$ \\
\hline $\mathrm{H}_{\mathrm{A}}:$ median $\mathrm{WTA}(\mathrm{A} 2)>$ median $\mathrm{WTA}(\mathrm{B} 2)$ & $(0.34)$ \\
\hline
\end{tabular}

Notes: $p$-values are in parentheses.

We now turn to the testing of hypothesis 2 . We report estimated regression results of equation 1 in Table 4. Test results of hypothesis 1 using the regression equation 1 are reported in Table 5 in appendix. In regression equation 1 as discussed earlier the main coefficient of interest is $\beta_{7}$, the coefficient associated with the interaction between D2 and D3. Table 4 shows that $\beta_{7}$ is insignificant at any conventional level of significance. In other words we do not find any evidence of endowment effect of chocolate being sensitive to the number of units of pens in initial endowment. 
Table 4: Regression results

\begin{tabular}{cc|}
\hline Independent variables & Bid \\
Dummy-1 & $0.56^{* * *}$ \\
& $(0.18)$ \\
& \\
Dummy-2 & $-0.45^{* * *}$ \\
& $(0.15)$ \\
& \\
Dummy-3 & 0.24 \\
& $(0.16)$ \\
& $0.71^{* *}$ \\
& $(0.29)$ \\
& $0.79 * *$ \\
Int(Dummy-1\&Dummy-2) & $0.38)$ \\
& 0.14 \\
Int(Dummy-1\&Dummy-3) & $(0.25)$ \\
& -0.72 \\
Int(Dummy-2\&Dummy-3) & $(0.52)$ \\
\hline Int(Dummy-1\&Dummy-2\&Dummy-3) & $0.95 * * *$ \\
& $(0.11)$ \\
& 0.25 \\
& 0.23 \\
& 312 \\
\hline Adjusted $R^{2}$ & \\
Observations & \\
\hline
\end{tabular}

Notes: Robust standard errors in parentheses; $* \mathrm{p}<0.1, * * \mathrm{p}<0.05, * * * \mathrm{p}<0.0$

\section{Conclusion}

Our objective in this paper was to test existence of endowment effect in a two good setting without involving money and to test whether endowment effect of one good is dependent on the number of units of the other good in the initial endowment bundle. We tested our hypotheses using two goods: chocolates and pens. These two goods were found to be equally preferred in pilot survey conducted prior to the main experiments with subjects with similar profile. We elicited WTA and WTP in terms of pens using BDM technique in all experiments in all our main experiments. We found that median WTP of subjects with imaginary endowments exceeded that of subjects with same initial endowment but in physical units. However, in case of WTA experiments we did not find any statistically significant difference 
in median WTA between subjects with physical units of pens and chocolates as initial endowments and imaginary units of pens and chocolates as initial endowments. Therefore, we found weak evidence of endowment effect in the two-good setting (chocolates and pens). Additionally, we also tested whether endowment effect of chocolate is sensitive to the units of pens in the initial endowment. Towards this end we compared the difference between observed size of the endowment effects EW1 and EW2 in case of W1 and W2 as initial endowment bundles respectively. We found no statistically significant impact of change in number of units of pens in initial endowment on the endowment effect of chocolates.

To the best of our knowledge this study for the first time establishes existence of endowment effect purely in a neo-classical setting with two goods without involving money. In all our experiments we used BDM technique to elicit true preferences. Since under certain conditions BDM technique fails to elicit true preferences as shown by (Horowitz, 2006) it is imperative to conduct similar experiments in future with a different pool of subjects and elicit their preferences using some other incentive compatible elicitation methods like Vickery auction or take-it-or-leave-it (TIOLI) offer. 


\section{References}

Ariely D, Huber J, Wertenbroch K (2005) When do losses loom larger than gains? Journal of Marketing Research. 42(2):134-138.

Becker, G., DeGroot, M., Marschak, J. (1964).Measuring utility by a singleresponsesequential method.Behavioral Science, 9: 226-236.

Burson, A.K and Faro,D.(2013). The Endowment Effect is Unit Dependent: Multiple UnitHoldings Do Not Yield An Endowment Effect, Management Science59(3):545-555

Carmon, Ziv and Ariely,D. (2000). Focusing on the Forgone: Why Value Can Appear So Different to Buyers and Sellers, Journal of Consumer Research, 27 (December), 36070

Isoni, A., G.Loomes and R. Suggen (2011). The Willingness to Pay-Willingness to Accept Gap,the "Endowment Effect," Subject Misconceptions and Experimental Procedures for ElicitingValuations: Comment. American Economic Review 101(2):991-1011

Horowitz,J (2006). The Becker-DeGroot-Marschak mechanism is not necessarilyincentive compatible, even for non-random goods. Economic Letters 93(2006):6-11

Knetsch, J.L. (1989). The Endowment Effect and Evidence of Nonreversible Indifference Curves.American Economic Review 79(5):1277-1284.

List, John A. (2004). Neoclassical Theory Versus Prospect Theory: Evidence From The MarketPlace, Econometrica, 72(2): 615-625.

(2006). Using Hicksian Surplus Measure to Examine Consistency of IndividualPreferences: Evidence from a Field Experiment, Scandinavian Journal of Economics, 108(1):115-134. 
Odean, T., (1998). Are investors reluctant to realize their losses? Journal of Finance,53(5):1775-1798.

Plott, C.R. and Zeiler,K. (2005). The Willingness to Pay-Willingness to Accept Gap, the "Endowment Effect," Subject Misconceptions and Experimental Procedures for Eliciting

Valuations.American Economic Review 95(3):530-545.

... (2007). Exchange Asymmetries Incorrectly Interpreted as Evidence ofEndowment Effect Theory and Prospect Theory? American Economic Review 97(4):1449-1466. .(2011). The Willingness to Pay-Willingness to Accept Gap, the"Endowment Effect," Subject Misconceptions and Experimental Procedures for ElicitingValuations: Reply. American Economic Review 101(2):1012-1028.

Thaler, R. (1980.)Towards a Positive Theory of Consumer Choice.Journal of Economic Behavior and Organization (1): 39-60.

( 1985). Mental Accounting and Consumer Choice, Marketing Science,4(3): 199-

214. 